\title{
Assessment of Occupational Health Hazards Among four Different Areas: A Case study of Upstream Workers in Turkey
}

\author{
Longinos $\mathrm{SN}^{1 *}$, Longinou $\mathrm{DD}^{2}$ and Parlaktuna $\mathrm{M}^{1}$ \\ ${ }^{1}$ Department of Petroleum and Natural Gas Engineering, Middle East Technical University, \\ Ankara, Turkey \\ ${ }^{2}$ Department of Home \& Economics, Harokopio University Athens, Greece
}

*Corresponding author: Sotirios Nik Longinos, Department of Petroleum and Natural Gas Engineering, Middle East Technical University, Ankara, Turkey, Email: s.n.longinos@gmail.com

\section{Case Report \\ Volume 5 Issue 2}

Received Date: May 10, 2021

Published Date: May 27, 2021

DOI: $10.23880 /$ ppej-16000263

\section{Abstract}

The growing oil and gas industry is projected to prominently impact the lives and economies of modern communities around the world. Safety at work must be an implementation rather than a goal directed conduct. Accidents that arise from occupational health hazards have human, economic and social costs. This must not be a concern at only the individual level but also at the national and international level. This questionnaire examined the awareness of health hazards, the cognition of occupational casualties and disorders and actions taken to protect and/or audit dangers connected to these perils. Data from the questionnaire was analyzed by using descriptive statistics. In order to measure the agreement amongst responses for each question, Kendall's Coefficient of Concordance (W) was used. To estimate different health hazards and risks that normally occur in upstream activities, responses from participants of the questionnaire were used.

Keywords: Occupational Hazards; Turkey; Upstream Sector

\section{Introduction}

The growing oil and gas industry is projected to prominently impact the lives and economies of modern communities around the world [1]. The importance of Occupational Health is often taken for granted at the balconies of profit. Due to this, the workforce is complicit as they agree to work under conditions that do not observe the appropriate safety measures [2]. Both Employers and Employees must make sure safety measures are adhered to at the workplace. An appropriate safety measure at work reduces or eradicates the probability of injuries [3]. Safety at work must be an implementation rather than a goal directed conduct. The model of every organizational safety structure must state safety as a particular occasion of 'institutional work' [4]. According to International Labour Organization (ILO), 2.78 million people lose their lives due to vocational diseases and occupational injuries. Additionally, ILO has recorded that here are 374 million non-fatal work related injuries and diseases each year. These incidents amount to 3.94 per cent of global Gross Domestic Product (GDP) each year [5].

Occupational Safety is a complicated social phenomenon, where practices within organisations oblige to both instrumental functions (achieving goals) and expressive functions (revealing attitudes) [6]. This double standard is normally referred to as 'being safe' and 'feeling safe' [7]. The priority of every company must be the healthy wellbeing of its personnel who are their most important asset [8]. Accidents 


\section{Petroleum \& Petrochemical Engineering Journal}

that arise from occupational health hazards have human, economic and social costs. This must not be a concern at only the individual level but also at the national and international level [9-11]. Health hazards can be classified into physical health hazards (noise, lighting, vibration, ultraviolet radiation, ionizing radiation and extreme conditions of cold and heat etc.), chemical health hazards (particles, fibres, fumes and mist: carbon black, welding fume, oil mist, metals and metalloids: arsenic, cadmium, chromium, mercury, zinc, organic, solvents and compounds: acetone, hydrocarbons, benzene, inorganic gases: carbon monoxide, hydrogen supplied, sulphur dioxide etc.), mechanical/ergonomic health hazards (unshielded machinery, perilous designs in the workspace and hazardous tools etc.), psychological health hazards (when labour responsibilities include monotonous work, work that requires constant concentration, irregular working hours and excessive responsibility) and biological health hazards (exposure to some 200 biological agents, viruses, bacteria, parasites, fungi, moulds and organic dusts occur in particular occupational workspaces. Some of the most usual occupational illnesses ensuing from such exposures are Hepatitis B and C, tuberculosis, asthma and chronic parasitic diseases) [11-15].

This work examines the awareness of occupational hazards of national oil company of Turkey (TPAO).Turkish Petroleum Company (TPAO), which has its main office in Ankara, undertakes many upstream activities in Turkey and abroad, especially in Iraq and Azerbaijan. This research took place in four different regions of Turkey. These regions are Ankara (main offices), Batman (exploration for oil, biggest upstream activity region in all Turkey), East Thrace (exploration for gas) and Adiyaman (exploration for oil). The study was carried out using a questionnaire concerning the identification of health hazards. Below each question were multiple-choice answers. This questionnaire examined the awareness of health hazards, the cognition of occupational casualties and disorders and actions taken to protect and/ or audit dangers connected to these perils. The study lasted six months and had 261 participants. The participants included technical staff (drilling engineers, production engineers, geologists, seismic group (recorders), seismic staff (dynamite, cables, topography) and non-technical staff (drivers, secretaries, people who work in machine shop, people who work in the kitchen, people who work in human resources sector people who work in support services. The survey had an $87 \%$ response rate. That is to say, out of the 300 questionnaires that were distributed, only 261 came back fully answered. Each questionnaire was in six parts with the aim of examining the employee's knowledge on occupational health hazards. Answers to some of the questions were in the format of: Strongly Agree (SA), Agree (A), Disagree (D) and Strongly Disagree (SD). Others were in the form of rate according to; 4, 3, 2 and 1 .

\section{Results and Discussion}

Data from the questionnaires, which was about health hazards in upstream activities, was analyzed with Microsoft Excel. Data from the questionnaire was analyzed by using descriptive statistics. This date was then tabulated in a frequency table. Agreement amongst participants of the questionnaire was evaluated using Kendall's W statistics. In order to measure the agreement amongst responses for each question, Kendall's Coefficient of Concordance (W) was used. To estimate different health hazards and risks that normally occur in upstream activities, responses from participants of the questionnaire were used. The data obtained from the questionnaires were used to evaluate consciousness of workers in upstream activities. Kendall's Coefficient (W) was very instrumental in measuring the degree of accordance amongst responses in the collected data. $\mathrm{W}$ ranges from zero to one where zero implies no agreement and one implies total agreement.

Let us imagine that a respondent number $j$ is assigned to object $i$ in order to define its rank. Then;

The total rank of object $m$, with the total number of $n$ objects and in respondents is:

$$
R_{i}=\sum_{j=1}^{m} r_{i j}
$$

The equation of the mean value of the total rank is:

$$
\bar{R}=\frac{1}{2} m(n+1)
$$

Kendall's W:

$$
W=\frac{12}{\left[m^{2} n\left(n^{2}-1\right)\right]} S_{d}
$$

The sum of the squared deviation, $\mathrm{S}_{\mathrm{d}}$ is:

$$
S_{d}=\sum_{i=0}^{n}(R i-\bar{R})^{2}
$$

By utilizing Kendall's W-Statistics, of how employees from four (4) branches of Turkish Petroleum Co-operation (TPAO) were able to identify and detect occupational health Hazards at their various workplaces. Classifications of occupational health hazards in this context are biological health hazards, chemical health hazards, mechanical/ ergonomic health hazards, physical health hazards and psychological health hazards. In totality, two hundred and sixty-one (261) employees from all the four branches participated in this survey. The participants comprised of one hundred and eighty-six (186) technical staff and 


\section{Petroleum \& Petrochemical Engineering Journal}

seventy-five (75) non-technical staff. Ankara branch had forty-four (44) technicians and the highest number (96) of non-technicians participating. Thirty-five (35) technicians and twenty (20) non-technicians from Adiyaman responded to the questionnaires. Batman followed suit with the highest number (83) of technician participants. Twenty-two (22) non-technicians also participated at this branch. Thrace saw twenty-four (24) technician and seven (7) non-technician participants.

It must be noted that Technician in this context refers to an expert in the practical application of a science. Technical staff consisted of Seismic Group (Dynamite, Recorders, Topography and Cables), Well Completion Engineers, Reservoir Engineers, Drilling Engineers, Production Engineers and Geologists. The Non-Technical Group comprised of Support Service Personnel, Information Technologists (IT), Human Resource Personnel, Secretaries, Kitchen staff and Storekeepers.

Kendall's Coefficient (W), calculates the level of awareness by employees concerning the topic of discussion. It was observed that biological hazards are relatively minimal at TPAO. Thrace at $4 \%$ had the lowest level and Adiyaman at $13.5 \%$ had the relatively highest level of biological hazards awareness. However, employees at Ankaraand Batman bitterly complained that microbes could be found in some substances that they work with at their workstations. Participants from all branches were happy that proper environmental hygiene is not lacking in their workplaces. They were also happy that little or no hazardous waste is generated while working. The level of agreement on awareness of biological health hazards for Ankara, Adiyaman, Batman and Thrace are 9.2\%, 13.5\%, $9.6 \%$ and $4 \%$ respectively.

The level of awareness of chemical hazards was recorded at $76 \%$. This shows how the employees were well grounded in knowledge concerning chemical hazards. Ankara recorded the lowest level of awareness on chemical hazards while Batman recorded the lowest level. It was noted that Ankara and Adiyaman employees do not normally work with flammable, poisonous, corrosive substances, poisonous gases, dusts or fumes. It was noted that Batman and Thrace employees are likely to work with flammable, poisonous, corrosive substances, poisonous gases, dusts and fumes. A majority of the participants knew that chemical hazards are likely to affect one's health when they are exposed to them for a long period, hence effective safety measures must be observed. Additionally, they knew that exposure to chemical hazards could cause reproductive disorders, cardiovascular diseases, respiratory diseases and renal diseases. The level of agreement on awareness of chemical health hazards were 92.3\% for Ankara, 78.3\% for Adiyaman, $68.5 \%$ for Batman and $73 \%$ for Thrace. Concerning mechanical/ergonomic health hazards, $83 \%$ of the participants showed awareness on the identification of this hazard. Survey partakers from the branches knew that mechanical/ergonomic hazards could cause back, neck and body pains. Additionally they were aware about the essence of stretching for a while after sitting for a long period. They realized that they sometimes adopt an unhealthy posture while working. However, it was realized that both the technical and non-technical staff did not sit most of the time when they were on duty. The level of agreement on awareness of mechanical/ergonomic health hazards were $93 \%$ for Ankara, $80 \%$ for Adiyaman, $79 \%$ for Batman and $85 \%$ for Thrace.

The survey recorded that $73 \%$ of the participants were aware and could identify physical health hazards. Survey partakers from Ankara, Adiyaman, Batman and Thrace knew that exposure to radiations; high levels of heat, poor illumination, vibrations and high level of noise can cause health issues. It was noticed that proper safety measures were taken to counter these issues. However, participants from Ankara, Adiyaman and Thrace complained about relatively high levels of noise in their workplaces. It was recorded that their workplaces do not shake as an outcome of vibration from workplace machines and equipment. The level of agreement on awareness of physical health hazards were $84 \%$ for Ankara, $77 \%$ for Adiyaman, $62 \%$ for Batman and $87 \%$ for Thrace. In general, the level of awareness and identification of psychosocial health hazards was recorded at $66 \%$. Participants from all TPAO branches knew that psychosocial hazards could cause hypertension, anxiety, boredom and the like. Ankara participants complained that their workload is very challenging but were content with their unit or department. This situation in Ankara was same for Thrace. There was a similar case of high workload in Adiyaman but a majority of the participants wanted to be transferred to another unit or department. The scenario in Adiyaman was same for Batman. It was recorded that survey partakers neither complained about bad relationships between superiors and subordinates nor faced any kind of aggression or harassment in their place of work. The level of agreement on awareness of psychosocial health hazards were $69 \%$ for Ankara, $63 \%$ for Adiyaman, $67 \%$ for Batman and $71 \%$ for Thrace.

Awareness levels of the effectiveness of occupational health practices employed at TPAO branches was also talked. In general, $91 \%$ of the participants were happy about these health practices. Participants from Ankara, Adiyaman, Batman and Thrace were happy that they receive periodic calls for a health examination as well as monitoring and surveillance. Additionally, survey partakers from Ankara, Adiyaman and Batman confirmed that they had adequate training from TPAO after employment. However, this was not the same case in Thrace. Adiyaman, Batman and Thrace 


\section{Petroleum \& Petrochemical Engineering Journal}

participants found PPE provided by management to be adequate and appropriate. However, Ankara participants were not content with their PPEs. Effective HSE policies were recorded to be in effect and properly implemented in all branches. Interestingly, survey participants from all branches bitterly complained that Management is not completely committed to their health and well-being and there is no functional and active OHS System in place in their units. The level of agreement on awareness of effective occupational health practices were 88\% for Ankara, 80\% for Adiyaman, $100 \%$ for Batman and $74 \%$ for Thrace.

The survey noticed that Thrace workspaces were highly safe in terms of the biological hazard at $4 \%$ and Adiyaman had a relatively highest level at $13.5 \%$. Ankara recorded the highest level of chemical level awareness and identification at $92 \%$ while Batman recorded the least at $66 \%$. Ankara continued with its supremacy in mechanical/ ergonomic health hazard identification and awareness at 93\% and Batman recorded the least 79\%. Thrace showed dominance in physical health hazard identification and awareness at $87 \%$ and Batman recorded the least at $62 \%$. In psychological health hazard identification and awareness, Thrace was first at $71 \%$ and Adiyaman was last at $63 \%$. With level of agreement on effective occupational health practices, Batman recorded excellent dominance at a perfect score while Thrace recorded the least at $74 \%$. In summary, staff at TPAO is highly aware and can identify physical health hazards, chemical health hazards, mechanical/ergonomic health hazards, psychological health hazards and biological health hazards at their various workstations. Figure 1 shows the total outcomes for the four different regions in Turkey.

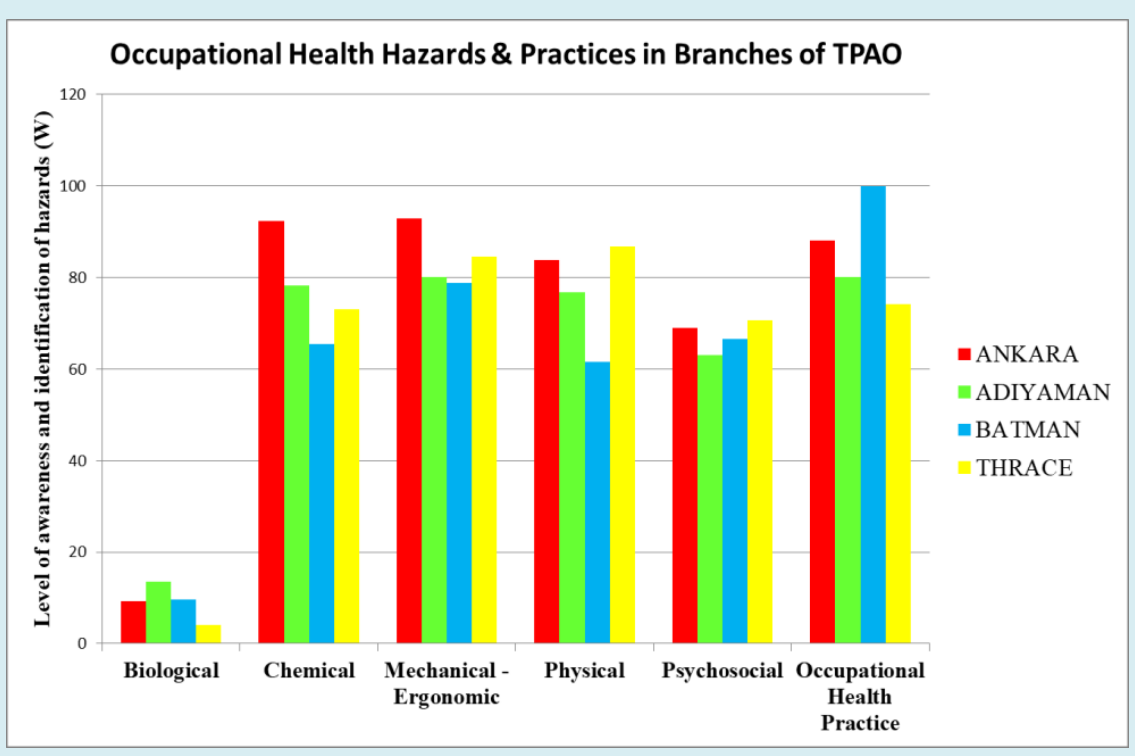

Figure 1: Level of Awareness of Occupational Health Hazards and Practices in the 4 branches of TPAO.

\section{Conclusion}

The survey was carried out at four branches of Turkish Petroleum Co-operation (TPAO). The main aim of the study was to identify occupational health hazards as well as identify effective occupational health practices and to test the knowledge of employees on the awareness and identification of health hazards. Occupational health hazards identification, health hazard awareness by employees, risks associated to these hazards and effective policies and implementation of occupational health practices is very important in the protection, promotion and rehabilitation of the health and well-being of employees at TPAO. From this study, it could be deduced that management of TPAO effectively implements effective health, safety and environment (HSE) policies.
However, more could be done to implement effective occupational health policies (OCP) especially at Thrace branch.

\section{References}

1. Moreau DTR, Neis B (2009) Occupational health and safety hazards in Atlantic Canadian aquaculture: Laying the groundwork for prevention. Marine Policy 33(2): 401-411.

2. Longinos SN, Qadri YM, Parlaktuna M (2017) Health and Safety Conditions in Four Major Industrial Sectors of Pakistan from 2010 to 2015. International Journal of Petroleum and Petrochemical Engineering 3(4): 102- 


\section{Petroleum \& Petrochemical Engineering Journal}

110.

3. Rae A, Provan D (2019) Safety work versus the safety of work. Safety Science 111: 119-127.

4. Gilbert C (2018) Safety: A matter for "Professionals"? In: Laroche H (Ed.), Beyond Safety Training. Springer International Publishing, Cham.

5. International Labour Organization (ILO).

6. Islam G, Zyphur MJ (2009) Rituals in organizations: A Review and Expansion of Current Theory. Group Organization Manage 34(1): 114-139.

7. Safety Institute Australia (2015) How to shift from reactive to proactive OHS.

8. Eyayo F (2014) Evaluation of Occupational Health Hazards among Oil Industry Workers: A Case Study of Refinery Workers, IOSR-JESTFT 8(12): 22-53.

9. Longinos SN, Parlaktuna M (2018) Occupational Accidents in energy sector: A case study of Turkish. Petroleum industry ISCSM-14 ${ }^{\text {th }}$ International Symposium of Continuous Surface Mining, Turkey.
10. Manoj Kumar RM, Karthick RB, Bhuvaneswari V, Nandhini N (2017) Study on Occupational Health and Diseases in Oil Industry. IRJET 4(12): 954-958.

11. WHO.

12. Kougioumtzi M (2015) Occupational Health and Security. Master Thesis, Technical Institute of Kavala, Greece.

13. Rick J, Briner RB, Daniels K, Perryman S, Guppy A (2001) Critical review of psychosocial hazard measures. Contract Research Report 356/2001.

14. Kortum E (2011) Psychosocial risks and work related stress in developing countries: a call for research and action in policy development. PhD Thesis, University of Nottingham, England.

15. Asumeng MA, Acquah-Coleman R, Dadzie JJ (2015) Addressing Psychosocial Hazards and Improving Employee Psychological Wellbeing in the Ghanaian Banking Industry: Application of Organization Development Intervention Using Action Research Model. American Journal of Applied Psychology 4(5): 120-128. 